\title{
Ergonomic stressors and upper extremity disorders in vehicle manufacturing: cross sectional exposure-response trends
}

\author{
Laura Punnett
}

\begin{abstract}
Objective-To evaluate the association between upper extremity soft tissue disorders and exposure to preventable ergonomic stressors in vehicle manufacturing operations.

Methods-A cross sectional study was conducted in one vehicle stamping plant and one engine assembly plant. A standardised physical examination of the upper extremities was performed on all subjects. An interviewer administered questionnaire obtained data on demographics, work history, musculoskeletal symptoms, non-occupational covariates, and psychophysical (relative intensity) ratings of ergonomic stressors. The primary exposure score was computed by summing the responses to the psychophysical exposure items. Multivariate regression analysis was used to model the prevalence of disorders of the shoulders or upper arms, wrists or hands, and all upper extremity regions (each defined both by symptoms and by physical examination plus symptoms) as a function of exposure quartile. Results-A total of 1315 workers (85\% of the target population) was examined. The prevalence of symptom disorders was $22 \%$ for the wrists or hands and $15 \%$ for the shoulders or upper arms; cases defined on the basis of a physical examination were about $80 \%$ as frequent. Disorders of the upper extremities, shoulders, and wrists or hands all increased markedly with exposure score, after adjustment for plant, acute injury, sex, body mass index, systemic disease, and seniority.

Conclusions-Musculoskeletal disorders of the upper extremities were strongly associated with exposure to combined ergonomic stressors. The exposure-response trend was very similar for symptom cases and for physical examination cases. It is important to evaluate all dimensions of ergonomic exposure in epidemiological studies, as exposures often occur in combination in actual workplaces.
\end{abstract}

(Occup Environ Med 1998;55:414-420)

Correspondence to: Dr Laura Punnett, Department of Work Environment, University of Massachusetts Lowell, One University Avenue, Lowell MA 01854, USA.

Accepted 12 January 1998
Vehicle manufacture, of cars in particular, is a major industry world wide, accounting for at least $7 \%$ of the manufacturing workforce in
Keywords: shoulder; neck; wrist; hand; musculoskeletal; psychophysical countries as diverse as the United States, Canada, Mexico, Brazil, Sweden, Spain, Japan, India, and Australia. ${ }^{1}$ Evidence exists as to the ergonomically stressful features of many jobs in vehicle assembly as well as the manufacturing stages that precede final vehicle assembly. ${ }^{2-14}$ Several epidemological studies have documented the musculoskeletal disorders associated with the demands of work in this industry. ${ }^{8}{ }^{12-19}$ However, publications are still few relative to the large variety of jobs and exposures and the size of the workforce involved.

The current study was sponsored by a joint company-union health and safety programme to evaluate the extent of exposure to ergonomic stressors in motor manufacturing; to assess the magnitude of musculoskeletal disorders of the upper extremity and related soft tissue; to seek aetiological associations, and to develop a prospective surveillance programme. Plant selection criteria included operations with large numbers of workers (to maximise the generalisability of the study findings), individual plant size and location, size and specificity of job classifications, and likely variety of ergonomic exposures. Ultimately, one engine plant and one stamping plant were selected.

Based on previous knowledge and preliminary process descriptions, it was anticipated that there would be multiple physical stressors present in each plant. Specifically, repetitive machine paced tasks, various postural stresses, and forceful exertions; segmental vibration exposures, contact mechanical stresses, and other exposures were considered likely to vary among jobs and plants. Thus, an exposure assessment method was required that could provide at least a crude evaluation of multiple exposure dimensions for each job, while not being overly resource intensive.

A variety of engineering based methods exist for precise measurement of exposures such as manual force requirements, joint angles, frequency or acceleration of motion, and vibration. However, each instrument measures only one exposure, and usually only at one body part at a time. The time required to perform instrumented analyses of multiple exposure dimensions at multiple body parts for each subject tends to limit their applicability to epidemiological research. ${ }^{20}$

One alternative means of characterising ergonomic exposures is to collect data directly from workers. Self reports may be obtained in various forms - such as the duration, frequency, or intensity of exposure. Estimates of relative exposure intensity based on psychophysical measures 
have both theoretical justification ${ }^{21-24}$ and at least moderate empirical validity in the field. ${ }^{325-27}$ For this study, a psychophysical instrument was developed to assess exposures for each subject in his or her usual job.

\section{Subjects and methods}

STUDY POPULATION

The study was conducted at one vehicle stamping plant and one vehicle engine assembly plant, both in Detroit, MI, USA. In the stamping plant, where car body parts are stamped from sheet metal, the production departments studied were large press, small press, and assembly (spot welding). In the engine plant, the machining and subassembly and assembly departments were selected, along with a group of workers employed in a variety of non-routine (less repetitive) jobs including maintenance, tool room, and some skilled trades. The first five department groups were selected because they were thought to involve activities with high ergonomic exposures, based on company records and the results of a preliminary screening survey. The last group was included in anticipation that it would have lower exposures and would thus serve as a control to anchor the planned analyses of exposure-response relations.

All active workers in the targeted departments $(n=1550)$ were recruited to participate in an interviewer administered questionnaire and physical examination of the musculoskeletal system. After the interviews were completed, subjects judged to present data quality problems or to spend most of their time in office rather than production work-for example, union officials - were excluded from statistical analysis. The exclusions were made blinded to exposure and health status.

\section{MORBIDITY DATA}

The health data were collected in 1992 in the stamping plant and 1993 in the engine plant, with the same protocol. All workers were interviewed and examined during the working day. A standardised questionnaire obtained demographic data, a detailed work history, and information on covariates such as height and weight, previous acute injuries, surgery, relevant medical conditions (endocrine, neurological, or collagen disease), alcohol intake, tobacco use, sports, and hobbies. Quetelet body mass index $\left(\mathrm{kg} / \mathrm{m}^{2}\right)$ was calculated. The questionnaire also sought information about musculoskeletal symptoms in the year preceding the interview; subjects responding positively received a questionnaire module designed for that specific body region. Each module asked about symptoms characteristic of specific syndromes; suddenness of onset; frequency; and duration within the past year; severity at interview, during the past week, and during the worst episode of the year; and previous medical treatment. In the wrist or hand module, a pain drawing was included on which the worker was asked to indicate symptomatic areas. The questionnaire was based on a published protocol ${ }^{28}$ and was similar to that used in numerous other musculoskeletal studies in the United States. ${ }^{129}$
A structured physical examination ${ }^{28}$ was also performed on all subjects. Active range of motion was used to screen for discomfort and restriction of motion; abnormal findings were followed by passive, and in some cases, restricted motions. Phalen's test for carpal tunnel syndrome, Finkelstein's test for deQuervain's disease, and a modified Adson's manoeuvre (numbness in the distal extremity after a period of forced extension and abduction of the shoulder) for shoulder dysfunction and brachial plexus irritation were also included. Sensory testing of vibration thresholds was performed on the index and little fingers of both hands. Grip and pinch strength testing by dynamometer was also carried out on both hands. For the average asymptomatic worker the examination took 15 to 20 minutes to complete.

Subjects were defined as "symptom cases" if they had prevalent pain or discomfort within the past year, which had begun after first employment at the company, and which had occurred at least 12 times, or for at least one week, or continuously within the past year (minimum duration or frequency). Subjects who reported the first onset of pain to be before their first employment at the company were excluded from data analysis. Subsets of symptom cases, with onset after first employment in the current plant, in the current job, or in the past year, were also analysed; the results did not differ substantively from those presented here. Physical examination cases were defined as having one or more findings on examination of the specified body part, plus symptoms at the same body part in the past year that had begun since employment at the company. These cases were defined for the neck, shoulder or upper arm, elbow or forearm, and wrist or hand, as well as the entire upper extremity-that is, subjects who met the case definition for at least one of the four regions of the upper extremity.

\section{ERGONOMIC ASSESSMENT OF EXPOSURE}

Exposure data on subjects' current jobs were collected by means of the questionnaire (for all workers) and by observation (for five of the six department groups). In the questionnaire, a set of items were included on exposure to nonneutral postures, work pace, vibration, manual forces to handle tools and parts, and mechanical pressures from hand held tools in the subject's usual job. The Borg CR-10 scale ${ }^{23}$ was used to grade subjects' responses from 0 to 10 .

With a scoring procedure based conceptually on the draft ergonomics standard of the United States Occupational Safety and Health Administration, ${ }^{30}$ each measure was rescored on a scale of 0 to 3 (except for machine pacing: no $=0$, yes $=1$ ) and the items were then summed with unit weighting (see appendix). The total exposure score had a possible range from 0 to 25 and was divided into quartiles $(0-6,7-12$, 13-18, and 19-25).

Observations were made for jobs in all of the study departments except for non-routine work, which (precisely because of its nonroutine nature) would have been very time intensive to observe in detail. Exposure to risk factors was assessed with a standardised 
Table 1 Demographic characteristics and baseline medical histories of motor stamping and engine plant workers, Detroit MI, USA, 1992-3 ( $n=1315$ before exclusions)

\begin{tabular}{lcccc}
\hline & $\begin{array}{c}\text { Stamping plant } \\
(n=694)\end{array}$ & \multicolumn{2}{c}{$\begin{array}{c}\text { Engine plant } \\
(n=621)\end{array}$} \\
\hline Age (y) (mean (SD)) & 46 & $(8)$ & 48 & $(9)$ \\
Seniority in company (y) (mean (SD)) & 21 & $(5)$ & $22(8)$ \\
Seniority in plant (y) (mean (SD)) & 14 & $(6)$ & 20 & $(9)$ \\
Seniority in job (y) (mean (SD)) & 14 & $(7)$ & 12 & $(9)$ \\
Sex male (n (\%)) & 542 & $(78)$ & 534 & $(86)$ \\
Quetelet body mass index (mean (SD)) & $27.1(4.7)$ & $28.0(5.0)$ \\
Current cigarette smokers (n (\%)) & 306 & $(44)$ & $291 \quad(47)$ \\
Current alcohol use (n (\%)) & 396 & $(57)$ & $368(60)$ \\
Previous upper extremity injury (n (\%)) & $236(34)$ & 244 & $(39)$ \\
Systemic disease (n (\%)) & 115 & $(17)$ & 123 & $(20)$ \\
Weekly outside activity (n (\%)) $\dagger$ & 432 & $(62)$ & 424 & $(68)$
\end{tabular}

${ }^{\star}$ History of diabetes mellitus, lupus, gout, thyroid, or kidney disease.

†Regular participation in sports, hobby, second job, or other activity every week.

checklist similar to that described by Stetson et $a l .^{5}$ Job descriptions, workstation dimensions, part and tool weights, and other engineering and production data were obtained and used; for example, production data and work cycle duration were used to compute numbers of parts produced or cycles performed a day. The postures recorded were shoulder flexion and abduction, forearm rotation, severe elbow flexion and extension, wrist flexion, extension, and deviation, pinching, trunk flexion, and twisting. Manual material handling elements were characterised by frequency, load weight, and load location. All observations were blinded as to workers' health status.

The key upper extremity items found were rescored to range from 0 to 1,2 , or 3 , to obtain a similar scale to the psychophysical exposure score. The nine items were summed; the total score had a range from 0 to 22 .

STATISTICAL ANALYSIS

All statistical analyses were performed with the SAS software package for personal computer. ${ }^{31}$ The crude prevalence of cases was computed by quartile of psychophysical exposure; the prevalence ratios for the second, third, and fourth quartiles were calculated in comparison with the first quartile, along with the Mantel test for trend. ${ }^{32}$ The prevalence of disorders of each body region, by exposure level, were stratified by each potential confounding variable in turn to test for homogeneity, and, if appropriate, to calculate the Mantel-Haenszel pooled odds ratio. ${ }^{33}$ Trends in prevalence by seniority, as a proxy for cumulative exposure, were also examined.

The proportional hazard regression procedure, modified as by Breslow, ${ }^{34}$ was used for multivariate analysis of the prevalence of disorders of the upper extremities, shoulders, and wrists, with definitions based on both symp- toms and physical examination. Tests of significance and prevalence ratios with 95\% confidence intervals were calculated from the maximum likelihood estimates of the coefficients and their standard errors. In each model, indicator variables for the second, third, and fourth quartiles of psychophysical exposure (low, moderate, and high) were included, with the first quartile (very low, or 0-6) as the reference value. The potential confounding variables of acute injury, sex, and systemic disease were also included in all models. Indicator terms for plant (engine or stamping), age and duration of employment (three strata each), high body mass index $(\geqslant 26 v<26)$, and weekly participation in second jobs, sports, or other recreational activities (yes or no) were also entered and tested for significance, with both backward and forward selection procedures. We report all models with covariate coefficients that were significant at $p \leqslant 0.05$.

\section{Results}

A total of 1315 hourly workers (694 stamping plant employees and 621 engine plant employees) were examined at baseline (participation rate $85 \%$ ). There were only small demographic differences between the two plants (table 1). After exclusion of 117 subjects (9\%) not working in production or with questionable data quality, the final study population comprised 1198 workers.

In this combined population, $36 \%$ had upper extremity disorders based on the symptom case definition and $30 \%$ on the physical examination. The engine plant had slightly higher rates of disorders of the shoulders or upper arms and the stamping plant slightly higher rates of wrist or hand, elbow or forearm, and neck disorders, with definitions based on either the symptom or the physical examination (table 2). Because of statistical power considerations, the remaining analyses concentrated on cases with disorders of the shoulders, wrists or hands, and entire upper extremities.

Non-occupational factors associated with these end points included age (in some subsets), sex, body mass index, tobacco consumption, ${ }^{35}$ previous acute injury, and systemic disease, but not alcoholic drinks a week, or regular recreational activity. Crude trends were seen with duration of employment in the current job or plant but not with duration of employment at the company, which was only weakly correlated with the first two of these variables.

Of the 1077 subjects from whom psychophysical exposure data were obtained, $32 \%$ were

Table 2 Prevalences of upper extremity musculoskeletal disorders: baseline survey, vehicle stamping and engine plants, 1992-3 ( $n=1198$ after exclusions)

\begin{tabular}{|c|c|c|c|c|}
\hline \multirow[b]{2}{*}{ Body region } & \multicolumn{2}{|l|}{ Stamping plant } & \multicolumn{2}{|l|}{ Engine plant } \\
\hline & $\begin{array}{l}\text { Symptom cases } \\
n(\%)\end{array}$ & $\begin{array}{l}\text { Physical examination } \\
\text { cases } n(\%)\end{array}$ & $\begin{array}{l}\text { Symptom cases } \\
n(\%)\end{array}$ & $\begin{array}{l}\text { Physical examination } \\
\text { cases } n(\%)\end{array}$ \\
\hline Neck & $64(10.6)$ & $36(5.7)$ & $24(4.2)^{\star \star}$ & $11(1.9)^{\star \star}$ \\
\hline Shoulder and upper arm & $84(13.8)$ & $77(12.3)$ & $95(17.2)$ & $81(14.2)$ \\
\hline Elbow and forearm & $55(8.9)$ & $49(7.8)$ & $32(5.7)^{\star}$ & $21(3.7)^{\star \star}$ \\
\hline Wrist and hand & $152(25.5)$ & $126(20.1)$ & $102(18.4)^{\star \star}$ & $83(14.6)^{\star \star}$ \\
\hline Any part of the upper extremity & $242(38.5)$ & $205(32.6)$ & $192(33.7) \dagger$ & $156(27.4)^{\star}$ \\
\hline
\end{tabular}

${ }^{\star} \mathrm{p} \leqslant 0.05,{ }^{\star \star} \mathrm{p} \leqslant 0.01,+\mathrm{p} \leqslant 0.10, \chi^{2}$ test of difference in prevalence between plants. 


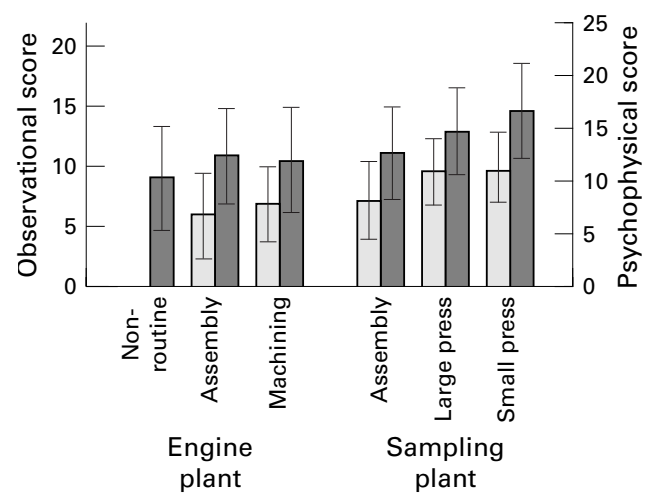

Figure 1 Exposure scores from psychophysical and observational data: means (SDs), by department. Baseline survey, car stamping and engine plants, 1992-3.

in the low level (score $7-12$ ) and $44 \%$ were in the moderate level (score 13-18) of exposure. The ergonomic exposure scores constructed from the psychophysical questionnaire items and the job observations both had roughly normal distributions. Exposures were generally lower for engine plant workers than stamping plant workers and the lowest exposures were in the engine plant non-routine jobs, as anticipated. The five department groups with both sets of ergonomic data were ranked in roughly the same order by the two methods, although there was a large variation in exposure score within each department (fig 1).

Among the six departments, disorders of the upper extremity occurred least often in the non-routine jobs. About $27 \%$ of those workers had symptoms, compared with $37 \%$ in the other engine plant departments and 39\% in the three stamping plant departments combined. The prevalence of cases based on physical examinations was $24 \%$ in the non-routine jobs, compared with $29 \%$ in the rest of the engine plant and $33 \%$ at the stamping plant.

The crude prevalence of disorders of the upper extremities, shoulders, and wrists in both plants, based on definitions from both symptoms and physical examinations, showed a strong trend with quartile of exposure score (fig 2). These trends were highly significant, both within plant and controlling for plant

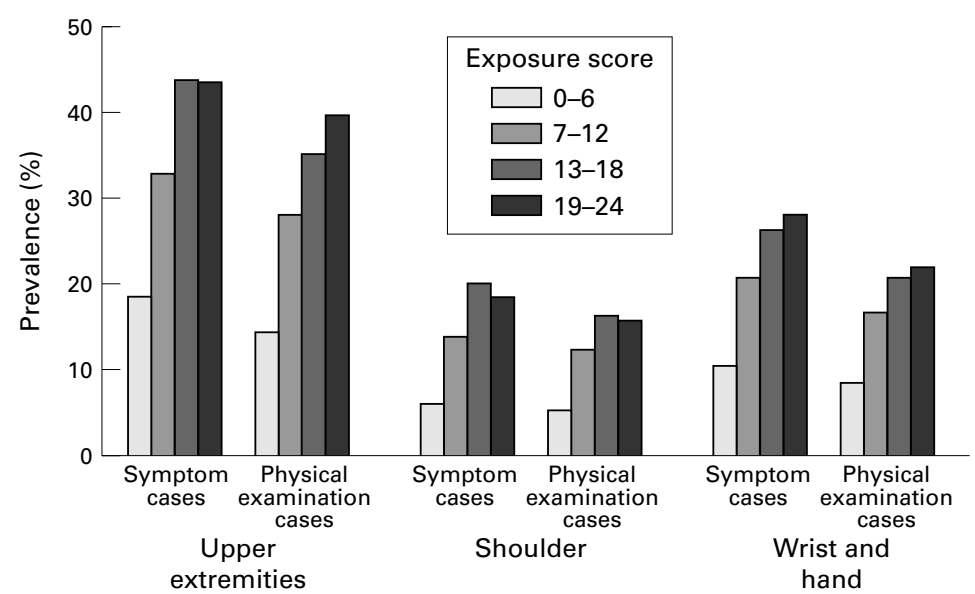

Figure 2 Crude prevalences of all disorders of the upper extremities, shoulder or upper arm, and wrist or hand, by quartile of ergonomic exposure score. Baseline survey, car stamping and engine plants, 1992-3 (subjects with data quality concerns were excluded). (tests of linear trend, for disorders of the upper extremities based on symptoms and physical examinations $\mathrm{p}<0.001$, and for shoulder or wrist disorders, $\mathrm{p} \leqslant 0.03$ ).

In the multivariate regression models, the overall trend in prevalence ratios (PRs) with increasing ergonomic exposure was remarkably consistent with that seen in the crude data for each of the end points. In the models of all upper extremity disorders, with acute injury, sex, and systemic disease included, there was a strong trend with increasing exposure level for both case definitions, although the risk levelled off for symptom cases in the highest quartile (table 3 ).

The models for shoulder or upper arm disorders also showed a strong effect of exposure level in all of the models, with a slightly steeper exposure-response trend for the symptom cases, although dropping slightly in the highest quartile (table 3 ). For each of the two case definitions, the best fit model was similar to that for all upper arm disorders but included a term for $>20$ years of employment in the current plant, instead of seniority with the company. The PRs for past shoulder injury showed a larger effect in these models than the corresponding estimates for all disorders of upper extremities or of wrists or hands.

In the multivariate models of disorders of wrists or hands, again there was a strong linear effect of the ergonomic exposure score with a plateau at the highest quartile (tables 3 and 4). For both end points, high seniority with the company was also significantly associated with disorders of wrists or hands, although systemic disease did not remain in the same model (disease prevalence was higher in older workers).

Terms for high body mass index and for weekly participation in sports or other leisure activities were not associated with disorders of wrists or hands in any of these models. The effect of sex on risk of these disorders was somewhat greater than the effect on all disorders of the upper extremities or shoulders and was the only covariate in these models with associations comparable in magnitude to the effect of exposure. None of the nonoccupational covariates had as much explanatory power as ergonomic exposure level.

\section{Discussion}

In this large study of vehicle manufacturing workers, the engine and stamping plant had similar crude prevalences of musculoskeletal disorders. The prevalence of disorders of upper extremities, shoulders and wrists, defined either by symptoms or physical examination, increased markedly with exposure to combined ergonomic stressors affecting upper extremities. Little change was noted when adjusting for covariates.

These results are consistent with those of Park et al, who found four different end points within the upper extremity to be significantly increased in the large press department of a stamping plant. ${ }^{16}$ Ergonomic control measures are feasible in principle for jobs in these types of operations ${ }^{2}$ and are known to have been implemented successfully both at the level of the job and in the organisation of the production process. ${ }^{8} 10$ 36-38 
Table 3 Prevalence ratios (95\% CIs) from multivariate regression models of upper extremity disorders on psychophysical exposure scores: vehicle stamping and engine plants combined, 1992-3*

\begin{tabular}{|c|c|c|c|c|c|c|c|c|}
\hline & \multicolumn{2}{|c|}{ Any upper extremity disorder } & \multicolumn{2}{|c|}{ Shoulder and upper arm disorder } & \multicolumn{4}{|c|}{ Wrist and hand disorder } \\
\hline & $A$ & $B$ & $A$ & $B$ & $\overline{A_{1}}$ & $A_{2}$ & $B_{1}$ & $B_{2}$ \\
\hline \multicolumn{9}{|l|}{ Exposure: } \\
\hline Very low† & 1.0 & 1.0 & 1.0 & 1.0 & 1.0 & 1.0 & 1.0 & 1.0 \\
\hline Low & $1.8(1.1$ to 2.8$)$ & $2.0(1.2$ to 3.4$)$ & 2.5 (1.1 to 5.6$)$ & $2.6(1.1$ to 6.2$)$ & $2.0(1.1$ to 3.6$)$ & $2.1(1.1$ to 3.8$)$ & $1.9(1.0$ to 3.8$)$ & $2.1(1.0$ to 4.0$)$ \\
\hline Moderate & $2.4(1.6$ to 3.8$)$ & $2.6(1.6$ to 4.3$)$ & $3.8(1.8$ to 8.2$)$ & $3.6(1.6$ to 8.3$)$ & 2.5 (1.4 to 4.6$)$ & $2.7(1.5$ to 4.9$)$ & $2.4(1.3$ to 4.7$)$ & $2.6(1.4$ to 5.0$)$ \\
\hline High & $2.3(1.4$ to 3.8$)$ & $2.8(1.6$ to 4.8$)$ & $3.5(1.5$ to 8.2$)$ & $3.3(1.3$ to 8.3$)$ & $2.5(1.3$ to 4.8$)$ & $2.7(1.4$ to 5.2$)$ & $2.3(1.1$ to 4.7$)$ & $2.6(1.2$ to 5.3$)$ \\
\hline Women & $1.5(1.2$ to 1.9$)$ & $1.9(1.5$ to 2.5$)$ & $1.6(1.1$ to 2.2$)$ & $1.7(1.2$ to 2.4$)$ & $2.0(1.5$ to 2.7$)$ & $2.2(1.6$ to 3.0$)$ & $2.4(1.8$ to 3.3$)$ & 2.7 (2.0 to 3.7$)$ \\
\hline $\begin{array}{l}\text { Upper extremity } \\
\text { injury }\end{array}$ & $1.4(1.1$ to 1.7$)$ & $1.5(1.2$ to 1.9$)$ & $2.8(1.8$ to 4.5$)$ & 2.5 (1.6 to 4.2$)$ & $1.3(1.0$ to 1.7$)$ & $1.3(1.0$ to 1.7$)$ & $1.5(1.1$ to 2.0$)$ & $1.6(1.2$ to 2.1$)$ \\
\hline Systemic disease & $1.3(1.0$ to 1.6$)$ & $1.3(1.0$ to 1.7$)$ & $1.5(1.1$ to 2.1$)$ & $1.6(1.1$ to 2.3$)$ & $1.2(0.9$ to 1.7$)$ & - & $1.3(1.0$ to 1.9$)$ & - \\
\hline $\begin{array}{l}\text { Years at company } \\
>25\end{array}$ & $1.1(0.9$ to 1.4$)$ & $1.3(1.0$ to 1.7$)$ & - & - & - & $1.3(1.0$ to 1.8$)$ & - & $1.4(1.0$ to 2.0$)$ \\
\hline Years at plant $>20$ & - & - & $1.5(1.1$ to 2.1$)$ & $1.6(1.2$ to 2.2$)$ & - & - & - & - \\
\hline
\end{tabular}

$\star$ Subjects with data quality concerns excluded. Number of subjects varies among models because of missing values for some covariates.

tReference value.

Table 4 Numbers of subjects in each regression analysis

\begin{tabular}{|c|c|c|c|c|c|c|}
\hline & \multicolumn{2}{|c|}{$\begin{array}{l}\text { Any upper } \\
\text { extremity }\end{array}$} & \multicolumn{2}{|c|}{$\begin{array}{l}\text { Shoulder and upper } \\
\text { arm }\end{array}$} & \multicolumn{2}{|c|}{ Wrist and hand } \\
\hline & Cases & Non-cases & Cases & Non-cases & Cases & Non-cases \\
\hline \multirow{2}{*}{$\begin{array}{l}\text { Model } \mathrm{A}=\text { symptom cases } \\
\text { Model } \mathrm{B}=\text { physical } \\
\text { examination cases }\end{array}$} & 401 & 675 & 167 & 875 & 234 & 797 \\
\hline & 332 & 744 & 145 & 931 & 193 & 883 \\
\hline
\end{tabular}

Several potential shortcomings are acknowledged. In particular, because of resource constraints, the group of jobs with the lowest exposures were not evaluated for ergonomic stressors by objective means. Thus, while the analyses reported here rely on the psychophysical exposure measures alone, we take comfort from the fact that the five departments with objective evaluations were ranked similarly by both systems. Also, responses to individual exposure questions were not highly correlated with each other, offering no evidence of subjects tending to answer every question with a positive (or a negative) response. This is consistent with the findings of Toomingas $\mathrm{et}^{\mathrm{al}} \mathrm{l}^{27}$ that people do not tend systematically to overrate or to underrate both exposures and symptoms.

The validity of psychophysical exposure ratings depends in part on subjects having a common frame of reference for the anchor points of the scales. ${ }^{23}$ Because of many lay offs in recent years in this industry, and consequent transfers among remaining workers, the subjects in this study had many years of work experience in the vehicle manufacturing industry and virtually all of them had performed other jobs before the current one. Thus, it is likely that they did have a common set of occupational experiences for comparison with the psychophysical scale ratings.

Selection bias seems to be an unlikely explanation for the study findings. Participation was high in both plants and in all departments. Subsequent exclusions were not associated with either symptom prevalence or exposure level. There was no way to determine whether the few non-respondent workers had different prevalences of musculoskeletal symptoms or findings, or different levels of exposure, than the respondents. However, given the size of the associations found, the overall consequence of any such selection effects was likely to have been low.

Of greater concern is the potential for differential selection out of the workforce and its effect on the estimated measures of association. At these two plants, workers had been employed on average by the company $>20$ years, and in their current jobs $>10$ years; this is typical of United States vehicle manufacturing in general. These workers undoubtedly represented a survivor population with respect to soft tissue disorders and might have had a higher threshold for exposure than a random group of new recruits. It has been shown that workers who develop musculoskeletal disorders in ergonomically stressful jobs are disproportionately likely to transfer to less exposed positions, ${ }^{29} 39$ and evidence for the healthy worker effect specifically in motor manufacturing has recently been reported by Park et al. ${ }^{17}$

There is circumstantial evidence for such a selection effect operating in the population studied here. The slight decrease in frequency of disorders in the group with highest exposure, in the presence of an otherwise strong exposure-response trend, is suggestive of such an effect, as is the inconsistency of the relation between risk and duration of employment.

Confounding is an unlikely explanation of our findings. Sports and other recreational activities and second jobs were not associated with the disorders under study. Covariates that were associated with at least some outcomes included sex, previous acute injury to the upper extremity (or to the same specific body part), systemic disease that might cause soft tissue symptoms, plant, and high age or plant seniority. However, these risk factors exerted little confounding influence: the PRs estimated in multivariate analyses were not notably different from the crude PRs.

It has been argued $^{40}$ that a simple linear summation of exposure items to construct a score, as was done here, is inadvisable, because of the judgments involved in assigning weightings to the individual items. It is true that the best weights to be applied to the items are not known and are especially needed if a scoring system is to be used in a wide range of occupations and industries. 
Nevertheless, in practical terms, there is a strong argument to be made for ongoing development and use of scoring systems - such as this one or similar ones used in other epidemiological investigations. ${ }^{41-43}$ It is essential that exposures to all occupational ergonomic stressors be assessed and used in the study of musculoskeletal disorders. Because of their multifactorial aetiology, ${ }^{44}$ and because aetiologically relevant exposures may be strongly correlated (positively or negatively) with each other, analyses of one ergonomic factor at a time may be subject to substantial confounding by other factors. A composite score or index also provides a relatively easy way to compare and prioritise many jobs, as well as to evaluate changes in exposure and risk over time.

The exposure score derived from the questionnaire was a powerful tool for predicting the risk of musculoskeletal disorders of the upper extremities. Such a tool could have great use in a workplace if administered to workers at the time of reporting symptoms to the in house medical department; this would facilitate the rapid identification of cases with high exposures that would be appropriate for early interventionthat is, the sentinel health event model of surveillance. ${ }^{45}$ Similarly, an ergonomic exposure index constructed from the questionnaire or from a comparable job analysis checklist could also be used readily as a routine screening tool to identify high risk jobs for intervention - that is, for hazard surveillance.

This study was funded by a contract from the United Auto Workers-Chrysler Joint National Committee (JNC) on Health and Safety and would have been impossible without the assistand Safety and would have been impossible without the assistance of many people. To name only a few, Twila Eshelman and Trudy Johnson Hall conducted physical examinations and
interviews, Andrew Bigelow performed job analyses, and Lei interviews, Andrew Bigelow performed job analyses, and Lei
Peng carried out most of the data management and statistical Peng carried out most of the data management and statistical analysis. Dr Rebecca Moreland was the liaison member for this
project from the Scientific Advisory Group to the UAWproject from the Scientific Advisory Group to the UAW-
Chrysler Joint National Committee. Dr Barbara Silverstein Chrysler Joint National Committee. Dr Barbara Silverstein
shared a draft copy of the OSHA exposure checklist when it was most needed. Dr David Wegman was generous, as always, with insights and advice based on his many years of commitment to scientific research in the service of worker health and safety.

\section{Appendix: Calculation of exposure score}

\begin{tabular}{lllll}
\hline \multirow{2}{*}{ Exposure item } & \multicolumn{3}{l}{ Original variable range } \\
\cline { 2 - 5 } & 0 & $0<x \leqslant 3.33$ & $3.33<x \leqslant 6.67$ & $6.67<x \leqslant 10$ \\
\hline Work pace & 0 & 1 & 2 & 3 \\
Grip force & 0 & 1 & 2 & 3 \\
Neck and shoulder postures & 0 & 1 & 2 & 3 \\
Arm postures & 0 & 1 & 2 & 3 \\
Wrist and hand postures & 0 & 1 & 2 & 3 \\
Contact stress from tool handle & 0 & 1 & 2 & 3 \\
Segmental vibration & 0 & 1 & 2 & 3 \\
Whole body vibration & 0 & 1 & 2 & 3 \\
Machine paced work & No $=0$ & & Yes $=1$ & \\
Total possible score $=$ & 25 & & & \\
\hline
\end{tabular}

1 International Labour Office. 1995 Yearbook of labour statistics. Geneva: International Labour Office, 1995.

2 Armstrong TJ, Joseph BS, Radwin RG, et al. Analysis of selected jobs for control of cumulative trauma disorders in automobile plants. Ann Arbor, MI: University of Michigan, Center for Ergonomics, 1986

3 Armstrong TJ, Punnett L, Ketner P. Subjective worker assessments of hand tools used in automobile assembly. $\mathrm{Am}$ Ind Hyg Assoc 7 1989;50:639-45.

4 Radwin RG, Armstrong TJ, VanBergeijk E. Vibration exposure for selected power hand tools used in automobile assembly. Am Ind Hyg Assoc f 1990;51:510-8.
5 Stetson DS, Keyserling WM, Silverstein BA, et al. Observaional analysis of the hand and wrist: A pilot study. Appl tional analysis of the hand and wrist:
Occup Environ Hyg 1991;6:927-37.

6 Burton NC, Boudreau Y, Grant KA. Health hazard evaluation report: Harvard Industries, Trim Trends Division, Bryan, Ohio. Cincinnati OH: National Institute of Occupational Safety and Health (US Department of Health and Human Services), 1992. (HETA-91-086-2235.)

7 Habes D, Burton NC, Baron S. Health hazard evaluation report: Scott Molders, Kent, Ohio. Cincinnati, OH: National Institute of Occupational Safety and Health (US Department of Health and Human Services), 1992. (HETA-91003-2232.)

8 Johansson JA, Kadefors R, Rubenowitz S, et al. Musculoskeletal symptoms, ergonomic aspects and psychosocial factors in two different truck assembly concepts. International fournal of Industrial Ergonomics 1993;12:35-48.

9 Keyserling WM, Stetson DS, Silverstein BA, et al. A checklist for evaluating ergonomic risk factors associated with
lith list for evaluating ergonomic risk factors associated with
upper extremity cumulative trauma disorders. Ergonomics 1993;36:807-31.

10 Keyserling WM, Brouwer M, Silverstein BA. The effectiveness of a joint labor-management program in controlling awkward postures of the trunk, neck, and shoulders: results of a field study. International fournal of Industrial Ergonomics 1993;11:51-65.

11 Lindström I, Ohlund C, Nachemson A. Validity of patient reporting and predictive value of industrial physical work demands. Spine 1994;19:888-93.

12 Punnett L, Fine LJ, Keyserling WM, et al. Back disorders and non-neutral trunk postures of automobile assembly workers. Scand f Work Environ Health 1991;17:337-46.

13 Fransson-Hall C, Byström S, Kilbom A. Self-reported physical exposure and musculoskeletal symptoms of the forearm-hand among automobile assembly line workers. $\mathcal{f}$ Occup Environ Med 1995;37:1136-44.

14 Fransson-Hall C, Byström S, Kilbom Å. Characteristics of forearm-hand exposure in relation to symptoms among
automobile assembly line workers. Am f Ind Med 1996;29: 15-22.

15 Nelson NA, Park RM, Silverstein MA, et al. Cumulative trauma disorders of the hand and wrist in the auto industry. Am F Public Health 1992;82:1550-2.

16 Park RM, Nelson NA, Silverstein MA, et al. Use of medical insurance claims for surveillance of occupational disease. An analysis of cumulative trauma in the auto industry. 7 Occup Med 1992;34:731-7.

17 Park RM, Krebs JM, Mirer FE. Occupational disease surveillance using disability insurance at an automotive stamping and assembly complex. F Occup Environ Med 1996;38:1111-23.

18 Park D. Application of survival analysis to CTD risk assessment. Proceedings of the Human Factors Society 36th Annual Meeting. Vol 1. Santa Monica, CA: Human Factors Society, 1992:783-7,

19 Byström S, Fransson-Hall C, Welander T, et al. Clinical disorders and pressure-pain threshold of the forearm and hand among automobile assembly line workers. I Hand Surg [Br] 1995;20:782-90.

20 Kilbom A. Assessment of physical exposure in relation to work-related musculoskeletal disorders: what information can be obtained from systematic observations? Scand $f$ Work Environ Health 1994;20(special issue):30-45.

21 Stevens JC, Cain WS. Effort in isometric muscular contractons related to force level and duration. Perception Psychophysics 1970;8:240-4.

22 Borg G, Ottoson D, eds, The perception of exertion in physical work. London: MacMillan, 1986.

23 Borg G. Psychophysical scaling with applications in physical work and the perception of exertion. Scand 7 Work Environ work and the perception of exertic
Health 1990;16(suppl 1):55-8.

24 Gamberale F. The perception of exertion. Ergonomics 1985; 28:299-308

25 Nathan PA, Keniston RC, Meadows KD, et al. Validation of occupational hand use categories. F Occup Med 1993;35: $1034-42$.

26 Wigaeus Hjelm E, Winkel J, Nygård C-H, et al. Can cardiovascular load in ergonomic epidemiology be estimated by self-report? f Occup Environ Med 1995;37:1210-17.

27 Toomingas A, Alfredsson L, Kilbom A. Possible bias from rating behavior when subjects rate both exposure and outcome. Scand 7 Work Environ Health 1997;23:370-7.

28 Silverstein BA, Fine LJ. Evaluation of upper extremity and low back cumulative trauma disorders: a screening manual. Ann Arbor, MI: University of Michigan, School of Public Ann Arbor, MI: University of Michigan,

29 Silverstein BA, Fine LJ, Stetson D. Hand-wrist disorders among investment casting plant workers. F Hand Surg [Am] 1987;12:838-44

30 Occupational Safety and Health Administration (US Department of Labor). OSHA draft proposed ergonomic protection standard: summaries, explanations, regulatory text, appendices. Occupational Safety and Health Reporter 1995;24:S3-248.

31 SAS Institute. SAS procedures guide, version 6, 3rd edition. Cary, NC: SAS Institute, 1990.

32 Mantel N. Chi-square tests with one degree of freedom: extension of the Mantel-Haenszel procedure. Fournal of the American Statistical Association 1963;59:690-700.

33 Mantel N, Haenszel W. Statistical aspects of the analysis of data from retrospective studies of disease. $\mathcal{F}$ Natl Cancer Inst 1959;22:719-48.

34 Breslow N. Covariance analysis of censored survival data. Biometrics 1974;30:89-99. 
35 White DJ. Musculoskeletal disorders related to cigarette smoking and tobacco use [PhD thesis]. Boston, MA: Boston University
School of Public Health, Department of Epidemiology, 1995.

36 Moore JS. Flywheel truing: a case study of an ergonomic intervention. Am Ind Hyg Assoc f 1994;55:236-44.

37 Bullinger H-J, Rally PJ, Schipfer J. Some aspects of ergonomics in assembly planning. International fournal of Industrial Ergonomics 1997;20:389-97.

38 Schütte M, Schüder D. Case study: investigation into the subjective strain at two differently designed automobile assembly workplaces. International fournal of Industrial Ergonomics 1997;20:413-22.

39 Östlin P. Negative health selection into physically light occupations. F Epidemiol Community Health 1988;42:1526.

40 Kemmlert K. A method assigned for the identification of ergonomic hazards: PLIBEL. Appl Ergonomics 1995;26: 199-211.
41 Estryn-Behar M, Kaminski M, Peigne E, et al. Strenuous working conditions and musculoskeletal disorders among female hospital workers. Int Arch Occup Environ Health 1990;62:47-57

42 Liira JP, Shannon HS, Chambers LW, et al. Long term back problems and physical work exposures in the 1990 Ontario health survey. Am F Public Health 1996;86:382-7.

43 Schierhout GH, Myers JE, Bridger RS. Musculoskeletal pain and workplace ergonomic stressors in manufacturing industry in South Africa. International fournal of Industrial Ergonomics 1993;12:3-11.

44 Armstrong TJ, Buckle P, Fine LJ, et al. A conceptual model for work-related neck and upper-limb musculoskeletal disorders. Scand $\mathcal{F}$ Work Environ Health 1993;19:73-84.

45 Maizlish N, Rudolph L, Dervin K, et al. Surveillance and prevention of work-related carpal tunnel syndrome: an application of the sentinel events notification system for occupational risks. Am f Ind Med 1995;27:715-29.

\section{Occupational and Environmental Medicine and the electronic age}

OEM has an Email address which is 100632.3615@compuserve.com. We welcome contact by Email, including letters to the editor. Many of our reviewers send us their reports by Email, helping to speed up the peer review process.
Our publishing system is now fully electronic, and authors are sending their revised copy to us on disk as well as paper. Watch for revised Instructions to Authors.

The Editor 